\title{
TINGKAT PENGETAHUAN TATALAKSANA TUBERKULOSIS PADA MAHASISWA KEDOKTERAN UNIVERSITAS MALIKUSSALEH
}

\author{
Cut Khairunnisa ${ }^{1}$, Cut Sidrah Nadira ${ }^{2}$ Yuziani $^{3}$ \\ ${ }^{1}$ Bagian Ilmu Kesehatan Masyarakat, Fakultas Kedokteran, Universitas Malikussaleh \\ ${ }^{2}$ Bagian Fisiologi, Fakultas Kedokteran, Universitas Malikussaleh \\ ${ }^{3}$ Bagian Farmakologi, Fakultas Kedokteran, Universitas Malikussaleh
}

\begin{abstract}
Abstrak
Pengetahuan tentang tuberkulosis pada mahasiwa kedokteran merupakan hal yang penting untuk dicapai. Karena sampai saat ini, tuberkulosis merupakan penyakit infeksi yang masih menjadi perhatian dunia. Data WHO menyebutkan sekitar 10 juta orang terinfeksi TB paru tahun 2018 dan 1,4 juta orang meninggal dunia. Tuberkulosis telah menjadi penyakit yang mengakibatkan kematian tinggi di dunia setelah penyakit kardiovaskuler. Sementara saat ini Indonesia menempati posisi tertinggi ketiga di dunia dengan jumlah kasus TB terbanyak. Walaupun strategi DOTS telah terbukti sangat efektif untuk pengendalian TB, tetapi beban penyakit TB di masyarakat masih sangat tinggi. Pengendalian TB sangat membutuhkan keterlibatan banyak pihak, pihak yang memiliki peran strategis dalam pengendalian TB ini salah satunya adalah sumberdaya manusia (SDM) kesehatan dalam hal ini adalah dokter yang memiliki kompetensi yang cukup mumpuni. Penelitian ini bertujuan untuk menganalisis sejauh mana pemahaman mahasiswa kedokteran dalam menanggulangi penyakit tuberkulosis setelah mereka menjalani perkuliahan pada Blok/mata kuliah sistem respirasi. Penelitian ini merupakan penelitian kuantitatif dengan pendekatan cross sectional. Sampel penelitian adalah mahasiswa FK Unimal yang telah mengikuti Blok Gangguan Sistem Respirasi yang berjumlah 208 yang dipilih secara random. Hasil penelitian menunjukkan bahwa tingkat pengetahuan mahasiwa FK Unimal tentang tuberkulosis secara umum, determinan dan tatalaksana tuberkulosis dominan dalam kategori cukup.
\end{abstract}

Kata Kunci: Tuberkulosis, Pengetahuan, Determinan TB,Tatalaksana TB

\section{Knowledge Level of Tuberculosis Management in Medical Students at Malikussaleh University}

\begin{abstract}
Knowledge about tuberculosis in medical students is an important thing to achieve. Because until now, tuberculosis is an infectious disease that is still a global concern. WHO data states that around 10 million people were infected with pulmonary TB in 2018 and 1.4 million people died. Tuberculosis has become a disease that causes high mortality in the world after cardiovascular disease. Meanwhile, Indonesia currently occupies the third highest position in the world with the highest number of TB cases. Although the DOTS strategy has proven to be very effective for TB control, the burden of TB disease in the community is still very high. TB control really requires the involvement of many parties, those who have a strategic role in TB control, one of which is health human resources (HR) in this case are doctors who have sufficient competence. This study aims to analyze the extent of understanding of medical students
\end{abstract}


in tackling tuberculosis after they undergo lectures on the respiratory system block/course. This research is a quantitative research with a cross sectional approach. The research sample was Unimal Medical Faculty students who had followed the Respiratory System Disorder Block, amounting to 208 randomly selected. The results showed that the level of knowledge of Unimal Medical Faculty students about tuberculosis in general, the determinants and treatment of tuberculosis were dominant in the sufficient category.

Keywords: Tuberculosis, Knowledge, Determinants of TB, TB Management

\section{PENDAHULUAN}

Tuberkulosis merupakan salah satu penyakit menular yang menjadi penyebab utama masalah kesehatan, data dari World Health Organization (WHO) 2019 menunjukan Tuberkulosis menjadi salah satu dari sepuluh penyebab utama kematian di seluruh dunia. Secara global, diperkirakan 10 juta (kisaran, 9,0-11,1 juta) terinfeksi TB pada tahun 2018 dan ini merupakan jumlah yang telah relatif stabil dalam beberapa tahun terakhir (1). Secara global, diperkirakan terdapat 10,0 juta orang (kisaran 9,0-11,1 juta) menderita penyakit TB pada 2017. Tuberkulosis dialami oleh 5,8 juta pria, 3,2 juta wanita dan 1,0 juta anak-anak (2).

Indonesia merupakan negara dengan pasien TB terbanyak ke 3 di dunia setelah India dan Cina. Diperkirakan jumlah pasien TB di Indonesia pada akhir 2019 sekitar 845.000 lebih tinggi dibandingkan tahun 2018 yaitu 842.000 kasus. Dari jumlah tersebut, baru 68 persen yang ditemukan dan diobati. Saat ini angka notifikasi kasus TB di Indonesia sebesar 446.732. Berdasarkan angka notifikasi ini jumlah penderita TB pada laki-laki lebih banyak yaitu 1,4 kali dibandingkan pada perempuan. Hal ini disebabkan kemungkinan laki-laki lebih sering terpapar pada fakto risiko TBC misalnya merokok dan kurangnya kepatuhan minum obat (3).

Tingginya angka kejadian Tuberkulosis ini mengharuskan dunia memikirkan upaya penggulangannya. Salah satu indikator keberhasilan penanggulangan TB adalah CDR dan angka keberhasilan pengobatan (success rate/SR) (4). Untuk mewujudkan indikator ini sangat diperlukan sumber daya manusia (SDM) kesehatan yang nanti akan berperan dalam penanggulangan tuberkulosis. Pengembangan Sumber Daya Manusia dalam program TB bertujuan untuk menyediakan tenaga pelaksana program yang memiliki keterampilan, pengetahuan dan sikap (kompetensi) yang diperlukan dalam pelaksanaan program TB (4). 
Dokter merupakan salah satu SDM kesehatan yang dituntut memiliki kompetensi dalam penanggulangan TB. Oleh karena itu, untuk menghasilkan dokter dengan kompetensi yang sesuai harus dimulai sejak dalam proses pendidikan. Saat ini Konsil Kedokteran Indonesia telah mengenalkan kurikulum berbasis kompetensi dengan pendekatan SPICES (student centered, problem based, integrated, community based, elective,systematic) (5). Problem based learning (PBL) merupakan pendekatan atau kurikulum baru yang diterapkan pada dunia pendidikan kedokteran (6). Hal ini terjadi karena adanya faktor faktor yang menyebabkan perlunya inovasi pada pendidikan. Antara lain kebutuhan untuk menujukkan perubahan di masyarakat, ledakan informasi dalam dunia kedokteran dan disiplin yang sesuai, kebutuhan akan professional kesehatan yang kompeten tidak hanya pada patofisiologi atau penegakan diagnosa namun juga keterampilan non kognitif, dan juga perubahan pada hubungan antar profesi yang memerlukan kerjasama (7).

Sesuai dengan standar kompetensi dokter indonesia (SKDI 2012) yang dikeluarkan oleh Konsil Kedokteran Indonesia (KKI) menyebutkan bahwa penyakit tuberkulosis paru merupakan penyakit dengan tingkat kompetansi 4 (empat) yang merupakan level kompetensi tertinggi yaitu 4A. Penyakit dengan tingkat Kemampuan 4 menuntut seorang dokter untuk mampu membuat diagnosis klinis, melakukan penatalaksanaan secara mandiri suatu penyakit hingga tuntas (5). Dalam mencetak lulusan yang memiliki kompetensi yang standar secara nasional, seluruh fakultas kedokteran di Indonesia harus berpedoman kepada SKDI yang dikeluarkan oleh KKI.

Fakultas Kedokteran Universitas Malikussaleh (FK UNIMAL), merupakan salah satu institusi pendidikan dokter yang ada di Aceh juga dituntut untuk melahirkan calon dokter yang memenuhi kompetensi secara nasional. Pemenuhan kompetensi bagi calon dokter diharapkan mampu menyelesaikan permasalahan kesehatan yang ada di seluruh Indonesia. Sebagaimana diketahui bahwa jumlah kasus tuberkulosis di Indonesia memiliki urutan tertinggi ketiga di dunia setelah India dan cina. Oleh karena itu, lulusan dokter di Indonesia sangat diharapkan mampu melakukan penyelesaian kasus ini secara mandiri hingga tuntas, demikian halnya lulusan dokter dari FK UNIMAL.

\section{METODOLOGI PENELITIAN}

Penelitian ini dilakukan di Fakultas Kedokteran Universitas Malikussaleh. Variabel penelitian yang akan diukur adalah karakteristik mahasiswa FK Unimal yang telah 
menjalani perkuliahan pada Blok 2.4 Gangguan Sistem Respirasi, tingkat pengetahuan tuberkulosis, determinan tuberkulosis dan penatalaksaan tuberkulosis. Penelitian ini merupakan penelitian deskriptif dengan menggunakan desain cross sectional.

\section{HASIL DAN PEMBAHASAN}

\section{Hasil penelitian}

Total responden yang mengisi kuesioner adalah 208 orang. Pertanyaan kuesioner dibagi menjadi tiga bagian yaitu tingkat pengetahuan tuberkulosis, determinan tuberkulosis dan penatalaksaan tuberkulosis. Berikut adalah hasil penelitian yang diperoleh

\section{A. Gambaran Umum Tingkat Pengetahuan Mahasiswa tentang Tuberkulosis}

Pada tabel 1 terlihat bahwa sebagian besar mahasiswa kedokteran sudah mengetahui agen penyebab penyakit tuberkulosis yaitu sebanyak 203 orang $(97,6 \%)$. Pengetahuan mahasiswa tentang gejala klasik tuberkulosis dominan pada kategori baik yaitu sebesar 88 orang $(42,3 \%)$. Tingkat pengetahuan mahasiswa tentang pemeriksaan penunjang tuberkulosis terbanyak pada kategori kurang yaitu sebesar 93 orang $(44,7 \%)$. Sebagian besar mahasiswa sudah tahu tentang jenis imunisasi yang diberikan untuk pencegahan tuberkulosis yaitu sebanyak 195 orang (93,8\%). Tingkat pengetahuan mahasiswa tentang upaya pencegahan penularan tuberkulosis dominan berada pada kategori kurang yaitu sebanyak 101 orang $(48,6 \%)$.

Tabel 1. Gambaran Distribusi Pengetahuan Mahasiswa FK Unimal tentang Tuberkulosis

\begin{tabular}{llcc}
\hline No & \multicolumn{1}{c}{ Variabel } & Frekuensi & Persentase \\
\hline $1 . \quad$ Pengetahuan penyebab TB & & \\
& a. Tahu & 203 & 97,6 \\
& b. Tidak tahu & 5 & 2,4 \\
\hline \multicolumn{2}{l}{ Total } & 208 & 100 \\
\hline 2. Pengetahuan gejala klasik TB & & \\
& a. Baik & 88 & 42,3 \\
& b. Cukup & 64 & 30,8 \\
c. Kurang & 56 & 26,9 \\
\hline \multicolumn{2}{l}{ Total } & 208 & 100 \\
\hline 3. Pemeriksaan penunjang & & \\
& a. Baik & 41 & 19,7 \\
b. Cukup & 74 & 35,6 \\
c. Kurang & 93 & 44,7 \\
\hline Total & 208 & 100 \\
\hline \hline
\end{tabular}




\begin{tabular}{llc}
\hline 4. Imunisasi TB & & \\
a. Tahu & 195 & 93,8 \\
b. Tidak tahu & 13 & 6,3 \\
\hline Total & 208 & 100 \\
\hline 5. Upaya pencegahan TB & & \\
a. Baik & 31 & 14,9 \\
b. Cukup & 76 & 36,5 \\
c. Kurang & 101 & 48,6 \\
\hline Total & 208 & 100 \\
\hline
\end{tabular}

B. Gambaran Tingkat Pengetahuan Mahasiswa tentang Determinan Tuberkulosis

Pada penelitian ini, peneliti juga menganalisis pengetahuan tentang determinan tuberkulosis. Didapatkan data bahwa tingkat pengetahuan mahasiswa tentang faktor yang mempengaruhi kejadian tuberkulosis paling banyak berada pada kategori cukup yaitu sebanyak 92 orang $(44,2 \%)$. Sementara tingkat pengetahuan mahasiswa tentang permasalahan yang dapat meningkatkan beban penyakit tuberkulosis sebagian besar berada pada kategori kurang yaitu sebanyak 154 orang $(74,0 \%)$.

Tabel 2. Gambaran Distribusi Pengetahuan Mahasiswa FK Unimal tentang Determinan Tuberkulosis

\begin{tabular}{clcc}
\hline No & \multicolumn{1}{c}{ Variabel } & Frekuensi & Persentase \\
\hline 1. & Pengetahuan faktor yang mempengaruhi & & \\
TB & & \\
& a. Baik & 58 & 27,9 \\
b. Cukup & 92 & 44,2 \\
c. Kurang & 58 & 27,9 \\
\hline Total & 208 & 100 \\
\hline 2. & Beban TB & & \\
a. Baik & 54 & 26,0 \\
b. Kurang & 154 & 74,0 \\
\hline & Total & 208 & 100 \\
\hline
\end{tabular}

\section{Gambaran Tingkat Pengetahuan Mahasiswa tentang Tatalaksana Tuberkulosis}

Tingkat pengetahuan mahasiswa terkait tatalaksana tuberkulosis, sebanyak 167 (70,7\%) mahasiswa sudah tahu terapi yang harus diberikan kepada pasien TB pada fase intensif. Sebanyak 157 (75,5\%) mahasiswa sudah tahu tentang pilihan OAT yang harus diberikan pada kasus kambu/gagal pengobatan. Sebagian besar mahasiswa atau 134 $(64,4 \%)$ tidak tahu dosis rifampisin dan sebanyak $124(59,6 \%)$ mahasiswa tidak tahu cara pemberian obat rifampisin. Sebagian besar mahasiswa tidak tahu dosis isoniazid yaitu sebanyak 126 orang $(60,6 \%)$, dan sebanyak 131 orang $(63,0 \%)$ tidak tahu cara 
pemberian isoniazid. Sebanyak 149 mahasiswa $(71,6 \%)$ tidak tahu dosis pirazinamid dan sebanyak $125(60,1 \%)$ mahasiswa tidak tahu cara pemberian pirazinamid. Pengetahuan mahasiswa tentang dosis etambutol, sebagian besar mahasiswa tidak tahu dosis terapi etambutol yaitu sebanyak 146 orang (70,2\%) dan sebanyak $132(63,5 \%)$ mahasiswa tidak tahu cara pemberian etambutol. Sebagian besar mahasiswa tidak tahu dosis streptomisin yaitu sebanyak $131(63,0 \%)$ dan sebanyak $179(86,1 \%)$ mahasiswa tidak tahu cara pemberian streptomisin.

Tabel 3. Gambaran Distribusi Pengetahuan Mahasiswa FK Unimal tentang Tatalaksana Tuberkulosis

\begin{tabular}{|c|c|c|c|}
\hline No & Variabel & Frekuensi & Persentase \\
\hline \multirow[t]{4}{*}{1.} & Terapi fase intensif & & \\
\hline & a. Tahu & 167 & 70,7 \\
\hline & b. Tidak tahu & 61 & 29,3 \\
\hline & Total & 208 & 100 \\
\hline & OAT pada kasus kambuh/gagal pengobatan & & \\
\hline & a. Tahu & 157 & 75,5 \\
\hline & b. Tidak tahu & 51 & 24,5 \\
\hline & Total & 208 & 100 \\
\hline \multirow[t]{4}{*}{3.} & Dosis rifampisin & & \\
\hline & a. Tahu & 74 & 35,6 \\
\hline & b. Tidak tahu & 134 & 64,4 \\
\hline & Total & 208 & 100 \\
\hline & Cara pemberian rifampisin & & \\
\hline & a. Tahu & 84 & 40,4 \\
\hline & b. Tidak tahu & 124 & 59,6 \\
\hline & Total & 208 & 100 \\
\hline & Dosis isoniazid & & \\
\hline & a. Tahu & 82 & 39,4 \\
\hline & b. Tidak tahu & 126 & 60,6 \\
\hline & Total & 208 & 100 \\
\hline \multicolumn{4}{|c|}{ 6. Cara pemberian isoniazid } \\
\hline & a. Tahu & 77 & 37,0 \\
\hline & b. Tidak tahu & 131 & 63,0 \\
\hline & Total & 208 & 100 \\
\hline \multicolumn{4}{|c|}{ 7. Dosis pirazinamid } \\
\hline & a. Tahu & 59 & 28,4 \\
\hline & b. Tidak tahu & 149 & 71,6 \\
\hline & Total & 208 & 100 \\
\hline \multirow[t]{4}{*}{8.} & Cara pemberian pirazinamid & & \\
\hline & a. Tahu & 83 & 39,9 \\
\hline & b. Tidak tahu & 125 & 60,1 \\
\hline & Total & 208 & 100 \\
\hline \multicolumn{2}{|c|}{$\begin{array}{l}\text { 9. Dosis etambutol } \\
\text { a. Tahu }\end{array}$} & 62 & 29,8 \\
\hline
\end{tabular}




\begin{tabular}{lcc} 
b. Tidak tahu & 146 & 70,2 \\
\hline Total & 208 & 100 \\
\hline 10. Cara pemberian etambutol & & \\
a. Tahu & 76 & 36,5 \\
b. Tidak tahu & 132 & 63,5 \\
\hline Total & 208 & 100 \\
\hline 11. Dosis streptomisin & & \\
a. Tahu & 77 & 37,0 \\
b. Tidak tahu & 131 & 63,0 \\
\hline Total & 208 & 100 \\
\hline 12. Cara pemberian streptomisin & & \\
a. Tahu & 29 & 13,9 \\
b. Tidak tahu & 179 & 86,1 \\
\hline Total & 208 & 100 \\
\hline
\end{tabular}

\section{Pembahasan}

Dalam penelitian ini peneliti menemukan bahwa sebagian besar mahasiswa FK Unimal sudah mengetahui tentang bakteri penyebab tuberkulosis yaitu sebanyak 203 mahasiswa (97,6\%). Temuan ini hampir sama dengan penelitian (8) di Iran yang menemukan sebanyak 92,9\% mahasiswa kedokteran tahu penyebab tuberkulosis dan penelitian yang dilakukan oleh (9) di India, yang menemukan bahwa sebesar 100\% mahasiswa kedokteran tahu mikroba penyebab penyakit tuberkulosis. Pengetahuan mahasiswa FK Unimal tentang gejala klasik tuberkulosis berada pada kategori baik yaitu sebesar 88 orang $(42,3 \%)$. Persentase temuan ini lebih rendah dibandingkan penelitian (9) yang menemukan sebanyak 96\% mahasiswa kedokteran di India tahu tentang gejala tuberkulosis. Sebagian besar mahasiswa FK Unimal memiliki pengetahuan yang kurang tentang pemeriksaan penunjang yang diperlukan untuk menegakkan diagnosis tuberkulosis yaitu sebesar 44,7\%. Hal ini sedikit berbeda dengan temuan (10) yang menemukan sebanyak 54,1\% mahasiswa kedokteran di Roma, Italy tahu cara menegakkan diagnosis tuberkulosis. Sementara penelitian (11) di Nigeria Barat Daya menemukan hanya 33,6\% mahasiswa FK disana yang tahu cara menegakkan diagnosis tuberkulosis. Sebanyak 93,8\% mahasiswa FK unimal tahu tentang pilihan imunisasi untuk mencegah tuberkulosis adalah pemberian BCG. Hingga saat ini BCG merupakan satu-satunya vaksin yang diberikan kepada bayi untuk mencegah tuberkulosis. Pengetahuan mahasiswa FK Unimal dalam upaya pencegahan penularan tuberkulisis masih dominan pada kategori kurang yaitu sebesar 48,6\%. Banyak mahasiswa yang belum mengetahui bahwa upaya pencegahan tuberkulosis dapat berupa pemberian vaksin BCG khusus pada bayi, menjaga kebersihan lingkungan, 
menjaga serta meningkatkan imunitas tubuh, membiasakan pola hidup bersih dan sehat. Hasil penelitian ini tidak berbeda jauh dengan hasil penelitian (9) menemukan hanya $50 \%$ mahasiswa kedokteran di India yang tahu upaya pencegahan penularan tuberkulosis.

Pengetahuan mahasiswa tentang determinan tuberkulosis berupa faktor yang dapat mempengaruhi kejadian tuberkulosis sebagian besar berada pada kategori cukup yaitu sebanyak 44,2\%. Beberapa faktor yang mempengaruhi timbulnya penyakit tuberkulosis diantaranya adalah gizi buruk, adanya penyakit penyerta berupa Diabeter Mellitus dan HIV. Penyebab tingginya beban tuberkosis di setiap negara di dunia adalah tingginya angka kemiskinan (12), namun hanya 26\% mahasiswa FK Unimal tahu tentang ini, sebanyak $74 \%$ mahasiswa lainnya memiliki pengetahuan yang tentang beban tuberkulosis.

Pengetahuan mahasiswa FK Unimal tentang tatalaksana tuberkulosis secara umum sebesar $44,2 \%$ berada pada kategoi cukup. Sebagian besar mahasiswa sudah tahu pilihan OAT yang harus diberikan untuk terapi fase intensif yaitu pemberian 2RHZE/4RH dan sebagian besar mahasiswa juga sudah mengetahui OAT yang harus diberikan kepada pasien TB yang gagal pengobatan atau kambuh kembali setelah selesai pengobatan fase intensif yaitu berupa pemberian 2RHZES/RHZE/5RH3E3. Untuk pengetahuan terkait dosis dan cara pemberian OAT, sebagian besar mahasiswa FK Unimal tidak tahu dosis dan cara pemberian rifampisin, isoniazid, pirazinamid, etambutol maupun streptomisin. Hal ini tertera jelas pada tabel 2 diatas.

Secara umum pengetahuan tuberkulosis yang harus diketahui oleh mahasiswa kedokteran adalah agen yang menjadi penyebab tuberkulosis, gejala klasik yang umum dikeluhkan pasien seperti demam, batuk berdahak yang bisa disertai darah berlangsung lebih dari 2 minggu, penurunan berat badan, dan berkeringat pada malam hari (13). Pengetahuan umum lainnya tentang tuberkulosis yang harus dikuasai mahasiswa kedokteran adalah pemeriksaan penunjang yang digunakan untuk menegakkan diagnosis tuberkulosis baik pemeriksaaan laboratorium berupa pemeriksaan spesimen dahak maupun radiologik berupa rontgen thoraks (14). Pengetahuan tentang imunisasi dan upaya pencegahan juga sangat penting dikuasai oleh mahasiswa kedokteran. Hasil penelitian menunjukkan tingkat pengetahuan umum tuberkulosis pada mahasiswa kedokteran berada pada kategori cukup yaitu sebesar 53,8\%, pengetahuan tentang determinan dan tatalaksana tuberkulosis juga dominan berada pada kategori cukup yaitu 
masing-masing pengetahuan determinan $75,5 \%$ dan pengetahuan tatalaksana tuberkulosis $44,2 \%$. Hal ini tentu belum memenuhi standar kompetensi yang harus dikuasai oleh mahasiswa kedokteran. Dalam Standar Nasional Pendidikan Profesi Dokter Indonesia (SNPPDI) 2019 disebutkan bahwa penyakit tuberkulosis tanpa komplikasi memiliki standart komptensi 4, TB paru dengan komplikasi memiliki standar kompetensi 3A, TB Laten (Latent Tuberculosis Infection) dengan standar komptensi 4, dan TB dengan HIV memiliki standar komptensi 3A.

\section{KESIMPULAN}

1. Pengetahuan responden tentang tuberkulosis secara umum, determinan dan tatalaksana tuberkulosis dominan dalam kategori cukup

2. Masih banyak mahasiswa FK unimal yang tidak mengetahui dosis dan cara pemberian OAT.

\section{DAFTAR PUSTAKA}

1. WHO. Global Tuberculosis Report 2019. 2019.

2. WHO. Global Tuberculosis Report. World Health Organization; 2018.

3. Kemenkes RI. Tuberculosis Data and Information Center. Jakarta: Kementerian Kesehatan Republik Indonesia; 2018.

4. Kementrian Kesehatan RI. Republic of Indonesia Minister of Health Regulation No.67 of 2016 concerning Repetition of Tuberculosis. 2017.

5. Konsil Kedokteran Indonesia. STANDAR KOMPETENSI DOKTER INDONESIA. 2012.

6. Sari MI, Lisiswanti R, Oktaria D, Kedokteran BP, Kedokteran F, Lampung U. Pembelajaran di Fakultas Kedokteran : Pengenalan bagi Mahasiswa Baru. J Kedokt Unila. 2016;1:399-403.

7. Uzoigwe GO. CORRUPTION IN EDUCATION AND ASSESSMENT SYSTEMS : THE WAEC EXPERIENCE IN NIGERIA . Int Assoc Educ Assesment. 2013;1-16.

8. Behnaz F, Mohammadzade G, Mousavi-e-roknabadi RS, Behnaz F, Mohammadzade G. Assessment of knowledge, attitudes and practices regarding tuberculosis among final year students in Yazd, central Iran. Jounal Epidemiol Glob Heal. 2019;(April):81-5.

9. Rajgopal P, Souza MD, Chandra R. Tuberculosis knowledge and attitude in aspiring doctors and nurses - Is it time for our TB teaching methods to evolve? Indian J Rheumatol. 2016;1-6.

10. Laurenti P, Federico B, Raponi M, Furia G, Ricciardi W, Damiani G. Knowledge , experiences , and attitudes of medical students in Rome about tuberculosis. Med Sci Monit. 2013;865-74.

11. Olakunle OS, Oladimeji O, Olalekan AW, Bello AO, Akinleye C, Oluwatoyin OA. Knowledge of tuberculosis management using directly observed treatment short course therapy among final year medical students in South Western 
Nigeria. PanAfrican Med J. 2014;4-8.

12. Siroka A, Law I, Macinko J, Floyd K, Banda RP, Hoa NB, et al. The Effect of Household Poverty on Tuberculosis. Int J Tuberc. 2018;20(12):1603-8.

13. Knechel NA. Tuberculosis: Pathophysiology, Clinical Features, and Diagnosis. Crit Care Nurse. 2009;29(2).

14. Campbell IA, Bah-sow O. Clinical Review Pulmonary Tuberculosis : diagnosis and treatment. BMJ. 2006;332:1194-7. 